\title{
Complications Rates of Non-Oncologic Urologic Procedures in Population-based Data: A Comparison to Published Series
}

\author{
David S. Aaronson, Bradley A. Erickson, Veerasathpurush Allareddy, Jason L. Nelles, Badrinath \\ R. Konety
}

Department of Urology (DSA, BAE, VA, JSL), University of California San Francisco, San Francisco, $C A$, and Department of Urology (BRK), University of Minnesota, Minneapolis, USA

\begin{abstract}
Purpose: Published single institutional case series are often performed by one or more surgeons with considerable expertise in specific procedures. The reported incidence of complications in these series may not accurately reflect community-based practice. We sought to compare complication and mortality rates following urologic procedures derived from populationbased data to those of published single-institutional case series.

Materials and Methods: In-hospital mortality and complications of common urologic procedures (percutaneous nephrostomy, ureteropelvic junction obstruction repair, ureteroneocystostomy, urethral repair, artificial urethral sphincter implantation, urethral suspension, transurethral resection of the prostate, and penile prosthesis implantation) reported in the U.S.'s National Inpatient Sample of the Healthcare Cost and Utilization Project were identified. Rates were then compared to those of published single-institution series using statistical analysis.

Results: For 7 of the 8 procedures examined, there was no significant difference in rates of complication or mortality between published studies and our population-based data. However, for percutaneous nephrostomy, two published single-center series had significantly lower mortality rates $(\mathrm{p}<0.001)$. The overall rate of complications in the population-based data was higher than published single or select multi-institutional data for percutaneous nephrostomy performed for urinary obstruction $(\mathrm{p}<0.001)$.

Conclusions: If one assumes that administrative data does not suffer from under reporting of complications then for some common urological procedures, complication rates between population-based data and published case series seem comparable. Endorsement of mandatory collection of clinical outcomes is likely the best way to appropriately counsel patients about the risks of these common urologic procedures.
\end{abstract}

Key words: urology; complications, urologic procedures, informed consent

Int Braz J Urol. 2010; 36: 548-56

\section{INTRODUCTION}

Much of the knowledge regarding expected post procedural complications and rates of such complications is derived from reports of case series from single institutions or a small group of institutions. Practicing urologists generally use these rates of surgical complications and mortality in counseling patients prior to a surgical procedure. However, the reported incidence of complications in such exclusive case series may or may not reflect those of community practitioners.

There is growing interest in standardizing the process of informed consent in regards to what 
aspects are discussed and the probabilities of certain outcomes (1). In fact, the British Department of Health had previously issued a model consent form in 2002 for use throughout the National Health System (NHS) to address this matter. In addition, the American College of Surgeons (ACS) has released a Professional Code of Conduct in which section II. A describes the duty of obtaining informed consent to "include the estimated risks of mortality and morbidity" (2). Yet, it is probable that rates of complication or mortality during a given procedure may vary based on institution and provider.

It is unclear if complication rates from single or small groups of institutions are reflective of that observed in the community at large. One study did not find a difference between the complication rates of tertiary care centers and population-based data for radical cystectomy (3). Clearly, a system where physicians report their own complication rates would be the most accurate way of gaining informed consent. However, there is yet little incentive to collect this data by single physicians or institutions, as it is costly and labor intensive. We therefore sought to compare in-patient complication and mortality rates derived from population-based data obtained from a national data source to those from contemporary published single-institution case series for common urologic procedures.

\section{MATERIALS AND METHODS}

\section{Study Design}

We performed a retrospective analysis of the Nationwide Inpatient Sample (NIS) of the Health Care Utilization Project for 2000 to 2004. Briefly, the NIS is a $20 \%$ stratified sample of all community hospitals in the United States and contains 5 to 8 million records from approximately 1000 hospitals in 35 states (4). We used this national dataset to explore rates of complications and mortality following a selection of commonly performed urologic procedures and compared these rates to reported series in the literature.

\section{Patient Population}

We identified all patients with a primary urologic procedure noted for a single admission, ex- cluding those procedures performed for malignancy (radical prostatectomy and radical nephrectomy). These were identified by using the International Classification of Diseases, 9th Revision, Clinical Modification (ICD-9-CM) system (5). A list consisting of 8 groups of like procedures was constructed which excluded procedures done for malignancy (Table-1).

\section{Outcomes}

The primary outcome was in-patient rate of complication, group coded in the NIS using the clinical classification software (CCS) coding system (code 238; “complications of surgical procedures or medical care") and found under the category of secondary diagnosis (6). Our secondary outcome was a diagnosis of death (in hospital mortality).

\section{Literature Search}

Using PubMED we performed a literature search for large, contemporary (arbitrarily defined as published after 1995), and single-institutional case series for each of our 8 procedural groups examined. We further restricted our search to articles that included data on complication rates and were published in English-language journals. From these publications, we extracted complication rates and mortality. We excluded data from older literature as significant changes in the technology and practice of urology that have occurred since that time may make it hard to compare current practice realities to a time period older that that. We also wanted to ensure that we were utilizing reports from the immediate 5 year time period prior to our period of analysis (2000-2004) in order to ensure that any new procedures or technologies that had been used in published reports had sufficient time to become incorporated into routine practice. Keywords used for the literature search were complication rate, procedure name (nephrostomy, urethral sling/suspension, penile prosthesis, artificial urinary sphincter, transurethral prostatectomy), and mortality. 
Table 1 - Procedure definitions and corresponding ICD-9 codes.

\begin{tabular}{lcc}
\hline Procedure (N) & ICD-9 Code & Description \\
\hline Procedure 1 (26263) & 55.03 & percutaneous nephrostomy without stone fragmentation \\
& 55.04 & percutaneous nephrostomy with stone fragmentation \\
Procedure 3 (5074) & 55.87 & correct ureteropelvic junction obstruction \\
Procedure 4 (7464) & 56.74 & ureteroneocystostomy \\
Procedure 5 (2404) & 58.44 & urethral reanastamosis \\
& 58.45 & hypo-epispadias repair \\
& 58.46 & urethral reconstruction nec \\
Procedure 6 (1875) & 58.49 & urethral repair nec \\
Procedure 7 (39737) & 58.93 & implant artificial urinary sphincter \\
& 59.4 & suprapubic sling \\
& 59.5 & retropubic urethral suspension \\
Procedure 8 (117025) & 59.6 & paraurethral suspension \\
& 59.71 & levator muscle suspension \\
& 59.79 & urinary incontinence repair nec \\
& 60.21 & transurethral prostatectomy \\
Procedure 10 (6225) & 60.29 & other transurethral prostatectomy \\
& 60.3 & suprapubic prostatectomy \\
& 60.4 & retropubic prostatectomy \\
& 64.95 & insert non-inflatable penile prosthesis \\
& 64.96 & remove internal penile prosthesis \\
& insert inflatable penile prosthesis \\
\hline
\end{tabular}

*Procedures 2 and 9 were radical nephrectomy and radical prostatectomy, respectively. Procedures performed for malignancy were excluded from this study. ICD = International Classification of Diseases.

\section{Statistical Analysis}

For each procedure, the in-hospital complication rate from the HCUP dataset was compared to the rates from the publications identified in our literature search using Pearson's chi-square analysis. Mortality rates were compared using Fisher's exact test. All analyses were performed using STATA version 9.2 (Stata Corp., College Station, TX), and a two-tailed p-value $<0.05$ was considered significant.

\section{RESULTS}

Our literature search found 14 large contemporary published series that included complication statistics for 10 different procedures spanning all 8 of our procedure categories. The publications for each procedure are included in Table-2, along with the corresponding publication date, number of patients, and patient accrual period, when available (7-20).

For 7 of the 8 procedures examined, there was no significant difference in complication rates or mortality between published studies and our population-based data (Table-3). For percutaneous nephrostomy, two published single-center series had significantly lower mortality rates than the population-based data set $(0.31 \%$ and $0.32 \%$ vs. $2.7 \%$, p $<0.001)$. The overall rate of complications in the population-based data was higher than published data for percutaneous nephrostomy performed for urinary obstruction $(10.0 \%$ vs. $3.4 \%, \mathrm{p}<0.001)$, but similar to 
Table 2 - List of case series from our literature search.

\begin{tabular}{|c|c|c|c|c|c|}
\hline $\begin{array}{l}\text { Procedure } \\
\text { Category }\end{array}$ & First Author & Procedure Performed & N. Patients & $\begin{array}{c}\text { Date of } \\
\text { Publication }\end{array}$ & $\begin{array}{l}\text { Accrual } \\
\text { Period }\end{array}$ \\
\hline \multirow[t]{2}{*}{1} & Skolarikos (4) & $\begin{array}{l}\text { percutaneous nephrostomy } \\
\text { for obstruction }\end{array}$ & 650 & 2006 & $1996-2005$ \\
\hline & Osman (5) & $\begin{array}{l}\text { percutaneous nephrostomy } \\
\text { with nephrolithotomy }\end{array}$ & 315 & 2005 & $1987-2002$ \\
\hline \multirow[t]{2}{*}{3} & Moon (6) & laparoscopic pyeloplasty & 170 & 2006 & UNK \\
\hline & Jarrett (7) & laparoscopic pyeloplasty & 100 & 2002 & 1993-1999 \\
\hline 4 & Duong (8) & ureteroneocystostomy & 300 & 2003 & 1996-2002 \\
\hline \multirow[t]{3}{*}{5} & Perlmutter (9) & hypospadias repair & 316 & 2006 & 1999-2005 \\
\hline & $\mathrm{Fu}(10)$ & hypospadias repair & 294 & 2006 & $1993-2003$ \\
\hline & Hammouda (11) & epispadias repair & 42 & 2003 & 1998-2002 \\
\hline 6 & Costa (12) & implantation of AUS & 207 & 2001 & 1989-1998 \\
\hline \multirow[t]{2}{*}{7} & Levin (13) & tension-free vaginal tape & 331 & 2004 & UNK \\
\hline & Hodroff (14) & SPARC & 445 & 2005 & $2001-2003$ \\
\hline 8 & Borboroglu (15) & TURP & 520 & 1999 & 1991-1998 \\
\hline \multirow[t]{2}{*}{10} & Minervini (16) & $\begin{array}{l}\text { implant penile prosthesis } \\
\text { (both malleable and } \\
\text { inflatable) }\end{array}$ & 482 & 2005 & $1975-2000$ \\
\hline & Chiang (17) & $\begin{array}{l}\text { implant penile prosthesis } \\
\text { (various types) }\end{array}$ & 331 & 2000 & $1985-1996$ \\
\hline
\end{tabular}

AUS = artificial urinary sphincter; SPARC = supra-pubic arc sling; TURP = transurethral resection of the prostate, UNK $=$ unknown.

the rate observed when nephrostomy was performed with percutaneous nephrolithotomy $(10.1 \%)(8,9)$.

\section{COMMENTS}

The absence of a nationalized system (as seen in England and Canada) for reporting a surgeon's post-operative complications may impede the patient's ability to give informed consent. Currently, most physicians provide rates of complication and mortality for a given procedure, by citing single institutional case series oftentimes published by high-volume surgeons. We sought to examine the complication and mortality rates during various urologic procedures for the treatment of benign disease in a nationally (for the U.S.) collected dataset called the Nationwide Inpatient sample (NIS) collected by the Healthcare Cost and Utilization Project (HCUP) from 2000 to 2004. In addition, we hoped to compare these rates to those reported by single institutional series to address the question of whether the later are adequate for the use in gaining informed consent from patients. We found in this study, that for select urologic procedures, point estimates of complication and mortality discovered using population-based datasets were nearly comparable to those reported from single or groups of institutions. A prior report showed a similar finding for complication rates of radical cystectomy (3).

The finding of a higher rate of complication and mortality for patients undergoing nephrostomy in the population-based national dataset when compared to the cited single institutional series also deserves further scrutiny $(8,9)$. A breakdown of group 1 by the two ICD-9-CM codes contained within it 


\section{Complications Rates of Urologic Procedures}

Table 3 - Comparisons of complication rates and mortality rates between HCUP data set and published single-institution case series.

\begin{tabular}{|c|c|c|c|c|c|c|}
\hline Procedure & Study & $\mathbf{N}$ & Complications (\%) & p Value* & Mortality (\%) & p Valuet \\
\hline \multirow[t]{4}{*}{ Percutaneous nephrostomy } & & & & $<0.001$ & & $<0.001$ \\
\hline & HCUP & 26263 & $2621(10.00)$ & & $716(2.73)$ & \\
\hline & Skolarikos, et al. & 650 & $22(3.38)$ & & $2(0.31)$ & \\
\hline & Osman, et al. & 315 & $32(10.16)$ & & $1(0.32)$ & \\
\hline \multirow[t]{4}{*}{ Pyeloplasty } & & & & 0.16 & & 0.90 \\
\hline & HCUP & 5074 & $400(7.88)$ & & $4(0.08)$ & \\
\hline & Moon, et al. & 170 & $12(7.06)$ & & 0 & \\
\hline & Jarrett, et al. & 100 & $13(13.00)$ & & 0 & \\
\hline \multirow[t]{3}{*}{ Ureteroneocystostomy } & & & & 0.98 & & 1.00 \\
\hline & HCUP & 7464 & $749(10.03)$ & & $4(0.05)$ & \\
\hline & Duong, et al. & 300 & $30(10.00)$ & & 0 & \\
\hline \multirow[t]{5}{*}{ Urethral repair } & & & & $0.15 \dagger$ & & 1.00 \\
\hline & HCUP & 2404 & $152(6.32)$ & & $3(0.12)$ & \\
\hline & Perlmutter, et al. & 316 & $25(7.91)$ & & 0 & \\
\hline & $\mathrm{Fu}$, et al. & 294 & $27(9.18)$ & & 0 & \\
\hline & $\begin{array}{l}\text { Hammouda, et } \\
\text { al. }\end{array}$ & 42 & $1(2.38)$ & & 0 & \\
\hline \multirow{3}{*}{$\begin{array}{l}\text { Artificial urinary } \\
\text { sphincter }\end{array}$} & & & & 0.52 & & 1.00 \\
\hline & HCUP & 1875 & $407(21.71)$ & & $5(0.27)$ & \\
\hline & Costa, et al. & 207 & $49(23.67)$ & & 0 & \\
\hline \multirow[t]{4}{*}{ Urethral resuspension } & & & & 0.65 & & 1.00 \\
\hline & HCUP & 39737 & $2747(6.91)$ & & $10(0.03)$ & \\
\hline & Levin, et al. & 331 & $20(6.04)$ & & 0 & \\
\hline & Hodroff, et al. & 445 & $27(6.07)$ & & 0 & \\
\hline \multirow{3}{*}{$\begin{array}{l}\text { Transurethral resection } \\
\text { of prostate }\end{array}$} & & & & 0.95 & & 0.42 \\
\hline & HCUP & 117025 & 7126 (6.09) & & $358(0.31)$ & \\
\hline & $\begin{array}{l}\text { Borboroglu, et } \\
\text { al. }\end{array}$ & 520 & $32(6.15)$ & & 0 & \\
\hline \multirow[t]{3}{*}{ Penile prosthesis } & HCUP & 6225 & $616(9.90)$ & 0.23 & $8(0.13)$ & 1.00 \\
\hline & Minervini, et al. & 482 & $37(7.68)$ & & 0 & \\
\hline & Chiang, et al. & 331 & $36(10.88)$ & & 0 & \\
\hline
\end{tabular}

* p value by chi-square test except where noted; + p value by Fisher's exact test; HCUP = Healthcare Cost and Utilization Project.

demonstrated that 5,945 (23\%) patients underwent percutaneous nephrolithotomy (PNL) for treatment of nephrolithiasis and 20,318 (77\%) patients underwent simple nephrostomy tube placement for renal obstruction. One explanation for the higher complication rate found in the population-based data for those undergoing nephrostomy (including PNL) compared to our cited case series could be related to 
the heterogeneity of patients and procedures within group 1. Despite our desire to exclude patients with malignancy in this study (by excluding procedures performed for malignancy), it is conceivable that some individuals at the national level were given percutaneous nephrostomies to treat malignant renal obstruction. Presumably then this cohort would be sicker than those included in our case series would. Another explanation may have to do with the type of physicians placing the nephrostomy tube. The case series report data collected on patients treated only by urologists whereas our nationally representative sample likely contains patients treated by Interventional Radiologists as well.

It is important to note this study's other limitations. ICD-coding may inaccurately identify surgical complications (21-23). One must assume that single institutional data derived from direct chart abstraction is more comprehensive. However, chart review is subject to interpretation and selection bias on the part of the abstractors while claims data are not restrictive in this sense. In addition, we report only inpatient events as we are limited to this time frame by our dataset, but some complications occur after discharge.

Another limitation of this study is that we were unable to risk stratify patients by disease severity, age, gender, etc. The patients in the NIS might vary in these characteristics dramatically when compared to single institutional studies. However, tertiary centers responsible for the cited case series typically would treat sicker patients and thereby any bias would be expected to result in higher, not lower, rates of complications and mortality.

The selection of case series to compare to the data collected for this analysis is admittedly inexact. We attempted to select publications that were large, representative and would provide meaningful information from large institutional observational studies. However, it is possible that there are selection biases in terms of studies that are published and the comprehensiveness of our literature search itself. In addition, it is possible that some of the patients in these case series are also found in the NIS, though this number is likely quite small. Nevertheless, we feel that the selected studies provide a representative comparator.

\section{CONCLUSIONS}

In conclusion, for some common urological procedures, complication rates between populationbased data and published case series seem comparable if one were to completely discount underreporting of complications in administrative datasets. We do not, however, suggest that these data be interpreted as a justification for replacing self-collection of outcomes. Given the current health care climate in the U.S. and movements towards transparency, it is likely one day that provider-level data on morbidity and mortality will become available to better assist patients and physicians with healthcare decision-making. This is already underway in other countries and beginning to roll out in the U.S. through the comprehensive surgical registry, National Surgical Quality Improvement Project, supported by the American College of Surgeons.

\section{CONFLICT OF INTEREST}

None declared.

\section{REFERENCES}

1. Berman L, Dardik A, Bradley EH, Gusberg RJ, Fraenkel L: Informed consent for abdominal aortic aneurysm repair: assessing variations in surgeon opinion through a national survey. J Vasc Surg. 2008; 47: 287-295.

2. American College of Surgeon's Code of Professional Conduct. 2003 [cited $20 \mathrm{March}$ ]; Available from: http://www.facs.org/fellows_info/statements/stonprin. html\#anchor116209

3. Konety BR, Allareddy V, Herr H: Complications after radical cystectomy: analysis of population-based data. Urology. 2006; 68: 58-64.

4. Healthcare Cost and Utilization Project. Agency for Healthcare Research and Quality. Available online at URL: http://www.ahrq.gov/data/hcup/ (accessed February 9).

5. 1999 Hospital \& payor ICD-9-CM: international classification of diseases tr, clinical modification. 5th ed. Salt Lake City, Medicode, 1998.

6. HCUP: 2004 [cited 2004 January 13th]; Available from: http://www.hcup-us.ahrq.gov/toolssoftware/ccs/ AppendixASingleDX.txt 
7. Fu Q, Deng CL: Ten-year experience with composite bladder mucosa-skin grafts in hypospadias repair. Urology. 2006; 67: 1274-7; discussion 1277.

8. Skolarikos A, Alivizatos G, Papatsoris A, Constantinides K, Zerbas A, Deliveliotis C: Ultrasound-guided percutaneous nephrostomy performed by urologists: 10-year experience. Urology. 2006; 68: 495-9.

9. Osman M, Wendt-Nordahl G, Heger K, Michel MS, Alken P, Knoll T: Percutaneous nephrolithotomy with ultrasonography-guided renal access: experience from over 300 cases. BJU Int. 2005; 96: 875-8.

10. Jarrett TW, Chan DY, Charambura TC, Fugita O, Kavoussi LR: Laparoscopic pyeloplasty: the first 100 cases. J Urol. 2002; 167: 1253-6.

11. Moon DA, El-Shazly MA, Chang CM, Gianduzzo TR, Eden CG: Laparoscopic pyeloplasty: evolution of a new gold standard. Urology. 2006; 67: 932-6.

12. Duong DT, Parekh DJ, Pope JC 4th, Adams MC, Brock JW 3rd: Ureteroneocystostomy without urethral catheterization shortens hospital stay without compromising postoperative success. J Urol. 2003; 170: 1570-3; discussion 1573.

13. Perlmutter AE, Morabito R, Tarry WF: Impact of patient age on distal hypospadias repair: a surgical perspective. Urology. 2006; 68: 648-51.

14. Hammouda HM: Results of complete penile disassembly for epispadias repair in 42 patients. J Urol. 2003; 170: 1963-5; discussion 1965.

15. Costa P, Mottet N, Rabut B, Thuret R, Ben Naoum K, Wagner L: The use of an artificial urinary sphincter in women with type III incontinence and a negative Marshall test. J Urol. 2001; 165: 1172-6.
16. Levin I, Groutz A, Gold R, Pauzner D, Lessing JB, Gordon D: Surgical complications and medium-term outcome results of tension-free vaginal tape: a prospective study of 313 consecutive patients. Neurourol Urodyn. 2004; 23: 7-9.

17. Hodroff MA, Sutherland SE, Kesha JB, Siegel SW: Treatment of stress incontinence with the SPARC sling: intraoperative and early complications of 445 patients. Urology. 2005; 66: 760-2.

18. Borboroglu PG, Kane CJ, Ward JF, Roberts JL, Sands JP: Immediate and postoperative complications of transurethral prostatectomy in the 1990s. J Urol. 1999; 162: 1307-10.

19. Minervini A, Ralph DJ, Pryor JP: Outcome of penile prosthesis implantation for treating erectile dysfunction: experience with 504 procedures. BJU Int. 2006; 97: 129-33.

20. Chiang HS, Wu CC, Wen TC: 10 years of experience with penile prosthesis implantation in Taiwanese patients. J Urol. 2000; 163: 476-80.

21. McCarthy EP, Iezzoni LI, Davis RB, Palmer RH, Cahalane M, Hamel MB, et al.: Does clinical evidence support ICD-9-CM diagnosis coding of complications? Med Care. 2000; 38: 868-76.

22. Weingart SN, Iezzoni LI, Davis RB, Palmer RH, Cahalane M, Hamel MB, et al.: Use of administrative data to find substandard care: validation of the complications screening program. Med Care. 2000; 38: 796-806.

23. Lawthers AG, McCarthy EP, Davis RB, Peterson LE, Palmer RH, Iezzoni LI: Identification of in-hospital complications from claims data. Is it valid? Med Care. 2000; 38: 785-95.
Accepted after revision:

February 19, 2010

\section{Correspondence address:}

Dr. David S. Aaronson

UCSF Medical Center

Department of Urology

Ambulatory Care Center, Suite A633

San Francisco, CA, 94117, USA

Fax: +1 415 476-1239

E-mail: daaronson@urology.ucsf.edu 


\section{EDITORIAL COMMENT}

In this article by Aaronson et al., the authors compare the morbidity and mortality rates of nononcologic common urological procedures between national population-based data and single-institution published series. Except for percutaneous nephrostomy $(\mathrm{PN})$, the remainder procedures (ureteropelvic junction obstruction repair, ureteroneocystostomy, urethra repair, artificial urethra sphincter implantation, urethral suspension, transurethral resection of the prostate, penile prosthesis implantation) shared comparable rates between the two study groups. This conclusion is useful in the absence of a nationalized system for reporting a surgeon's complications and helps the patient to give informed consent.

Similar studies are encouraged in order to confirm if other urological procedures have comparable data or if there are statistically significant differences such as in the case of PN (this could be attributed to the availability of relevant recourses). Konety et al., demonstrated that morbidity and mortality rates after radical cystectomy in a population-based sample were comparable to those reported from individual centers (1). They found that larger centers in urban locations may have lower complication rates but only hospitals performing a high volume of cystectomies were associated with fewer primary surgery-related complications.

Except for registering all complications, surgeons are encouraged to classify their complications in each urological procedure. In the literature there are several standardized classification systems for reporting surgical complications $(2,3)$. The incorporation of such classification systems will help colleagues

\section{EDITORIAL COMMENT}

In this data comparison, the authors tried to establish whether it is reasonable in a general urology practice to counsel patients on perioperative compli- and patients to assess better and compare the risks of each operation.

In the future, provider-level data on morbidity and mortality should become available in favor of healthcare decision-making. Online registration by every urological surgeon (within hospitals, national and/or international associations) of the morbidity and mortality data for all standard urological procedures should be organized as this will meet relevant patient's expectations.

\section{REFERENCES}

1. Konety BR, Allareddy V, Herr H. Complications after radical cystectomy: analysis of population-based data. Urology. 2006; 68: 58-64.

2. Martin RC 2nd, Brennan MF, Jaques DP: Quality of complication reporting in the surgical literature. Ann Surg. 2002; 235: 803-13.

3. Clavien PA, Barkun J, de Oliveira ML, Vauthey JN, Dindo D, Schulick RD, et al.: The Clavien-Dindo classification of surgical complications: five-year experience. Ann Surg. 2009; 250: 187-96.

Dr. Athanasios Papatsoris, Dr. Stefanos Kachrilas \& Dr. Junaid Masood Department of Urology Barts and The London NHS Trust London, United Kingdom E-mail:agpapatsoris@hotmail.com

cations of selected urological procedures, based on figures from large, single institution published series. The study has a number of shortcomings (highlighted 
by the authors), of which the most obvious is the difficulty in extrapolating useful and practical information from a database like the Healthcare Cost and Utilization Project. One can only speculate as to why the complication rate for percutaneous nephrostomies was higher in the population-based dataset, and prob- ably reflects the lack of stratification of the reason for renal obstruction (e.g. advanced stage malignancy). The article does highlight the importance of accurate surgical audits (on institutional and national levels) to improve surgical outcomes and aid in the preoperative counseling of patients.

Dr. Angus T. Lecuona

Department of Urology

Tygerberg Hospital

University of Stellenbosch

South Africa

E-mail:angus@sun.ac.za 